
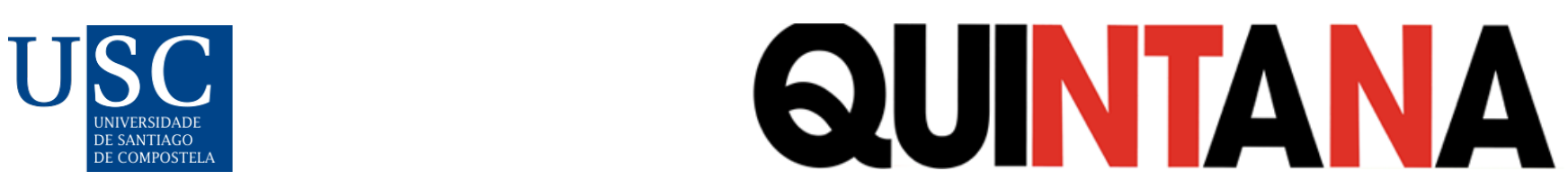

Quintana: revista do Departamento de Historia da Arte, (20), 2021. ISSN-e: 2340-0005

https://doi.org/10.15304/quintana.20.8120

Feitos e tendencias

\title{
AS MIRADAS DE ISAAC. UN ACHEGAMENTO Á INABARCABLE FIGURA DE DÍAZ PARDO
}

AS MIRADAS DE ISAAC. AN APPROACH TO THE IMMEASURABLE FIGURE OF DÍAZ PARDO

Agar Ledo Arias

Museo Nacional Centro de Arte Reina Sofía, España

\section{Nome da exposición:}

As miradas de Isaac

Comisariado:

Camilo Díaz Arias de Castro e Xosé Díaz Arias de Castro

Produción:

Cidade da Cultura, Xunta de Galicia, coa colaboración de Afundación

Lugar e datas:

Cidade da Cultura, Santiago de Compostela|6 de novembro de 2020 - 30 de maio de 2021; Afundación, A Coruña|29 de xuño - 28 de agosto de 2021; Afundación, Vigo|23 de setembro - 27 de novembro de 2021.

A exposición As miradas de Isaac é un responsable achegamento á inabarcable figura de Isaac Díaz Pardo (Santiago de Compostela, 1920-2012) no centenario do seu nacemento. A revisión entretece a biografía e a obra do autor a partir de nós históricos marcados por acontecementos cruciais na súa vida: o temporán apoio á república durante a campaña polo Estatuto de Autonomía de Galicia; o asasinato do pai, Camilo Díaz Baliño, paseado e fusilado polos fascistas; a invención do Laboratorio de Formas de Galicia, e o afastamento obrigado do seu proxecto de vida, Sargadelos, pouco antes da súa morte. A mostra recoñece a inmensidade dunha das figuras fundamentais para entender a cultura galega da segunda metade do século XX.

Comisariada polos irmáns Camilo e Xosé Díaz Arias de Castro, fillos de Díaz Pardo, a investigación articúlase en dez capítulos centrados nas variadas facetas que Isaac Díaz Pardo desenvolveu ao longo da súa vida. Foron pensados, cada un destes, xunto con investigadoras e investigadores especialistas: Iria-Friné Rivera Vázquez revisa o influxo do pai, referencia fundamental na vida e obra do autor; Rosario Sarmiento Escalona investiga a faceta como artista plástico; Ramón Villares atende á relación que Díaz Pardo mantivo co exilio; Teresa Pena Moreda e Fernando Arribas Arias estudan o vínculo entre arte e a industria no pensamento e traxectoria do intelectual; Andrés Varela Martínez conta a recuperación da memoria a través de institucións como o Seminario de Estudos Galegos; Daniel Beiras García-Sabell pescuda a filosofía do Laboratorio de Formas e a aplicación desta no deseño e na arquitectura do autor, e Carmela Montero García desvela a historia do Museo Carlos Maside. Todas e todos eles, xunto a Francisco Díaz-Fierros Viqueira, Xosé Ramón Fandiño, 
Charo Portela e Esperanza Mariño, comparten as achegas na publicación compilatoria editada con motivo da efeméride; libro-catálogo que vén a completar a bibliografía existente -aínda abertasobre quen foi unha das figuras máis complexas da cultura e artes galegas recentes. Se ben nos últimos anos se incrementaron os estudos sobre as súas aportacións ao pensamento galeguista e á restitución da memoria histórica a través da arte e da industria, sempre haberá espazo para historiar e interpretar a inmensa documentación que explica as reviravoltas do Laboratorio de Formas de Galicia, a institución ideada por Díaz Pardo e Luís Seoane durante os seus encontros en Buenos Aires. O Laboratorio recupera as liñas de pensamento da Xeración Nós e do Seminario de Estudos Galegos para articular, dende unha dimensión ética e experimental, todo o programa industrial e estético das "Industrias da memoria", nas que se inscribe a recuperación de Sargadelos, o Museo Carlos Maside, o Laboratorio Xeolóxico de Laxe, a editorial Edicíos do Castro, o Instituto Galego de Información, etc.

Vista da exposición As miradas de Isaac, Cidade da Cultura de Galicia, 2020. Autor da fotografía: Xosé Díaz.

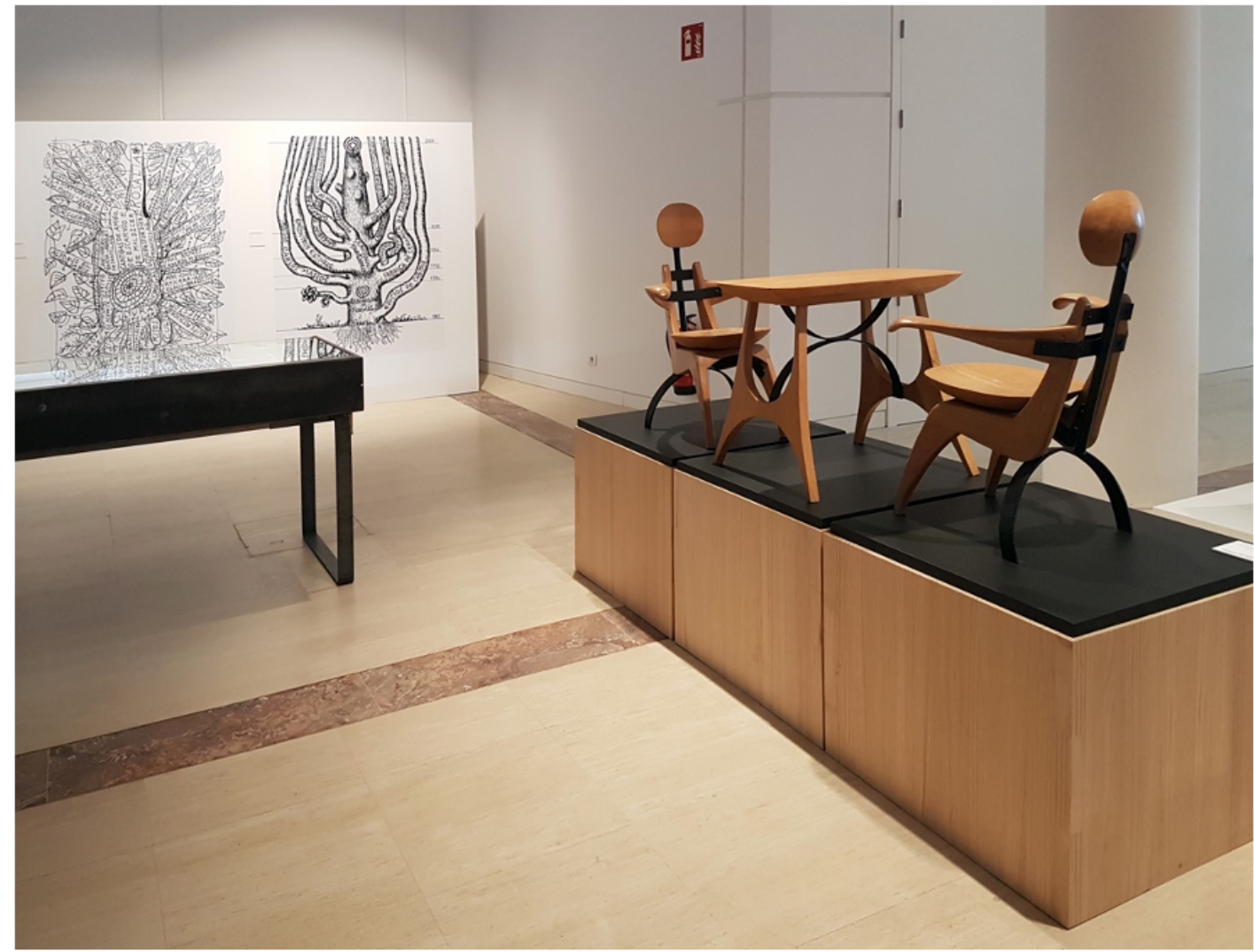

\section{PENSAR EN FRAGMENTOS}

A mostra entende cada apartado como unha desas pólas das árbores que deseñaba Díaz Pardo para explicar graficamente as ramificacións de cada idea; ramas que medran infinitamente. A metáfora arbórea sírvenos para explicar a importancia que neste proxecto curatorial posúe a extensión virtual dirixida pola investigadora María América Díaz, que fai accesible un inxente arquivo con centos de fotografías, vídeos e documentos históricos, moitos deles inéditos. A partir da documentación - unha das grandes achegas da exposición son os materiais que os comisarios 
recuperan do arquivo familiar-, a exposición cartografía ese complexo dispositivo que tiña como obxectivo principal a reactivación da memoria de Galicia a través das formas. Así, As miradas de Isaac propón a fragmentación en capítulos -o pensar en detalles que defendía Walter Benjamin, fronte ao pensar en xeneralidades- para comprender a complexidade tanto das propostas como dos tempos, pois a actividade dos protagonistas desta historia hai que entendela sempre en relación coa circunstancia histórica que lles tocou vivir e coa idea de país expandido coa que Luís Seoane se refería á súa terra: "Galicia abarca, dende hai séculos, ata os lugares onde os galegos emigran colectivamente". Dende a cidade de Buenos Aires, onde na década de 1950 coincidira a forza do exilio procedente de Galicia, Seoane e Díaz Pardo imaxinaron colectivamente a reinvención do páis.

Fotografía da pintada feita por Díaz Pardo na Praza do Obradoiro para apoiar o Estatuto de autonomía de Galicia, 1936. Autor: Isaac Díaz Pardo / Cortesía: Legado Díaz Pardo.

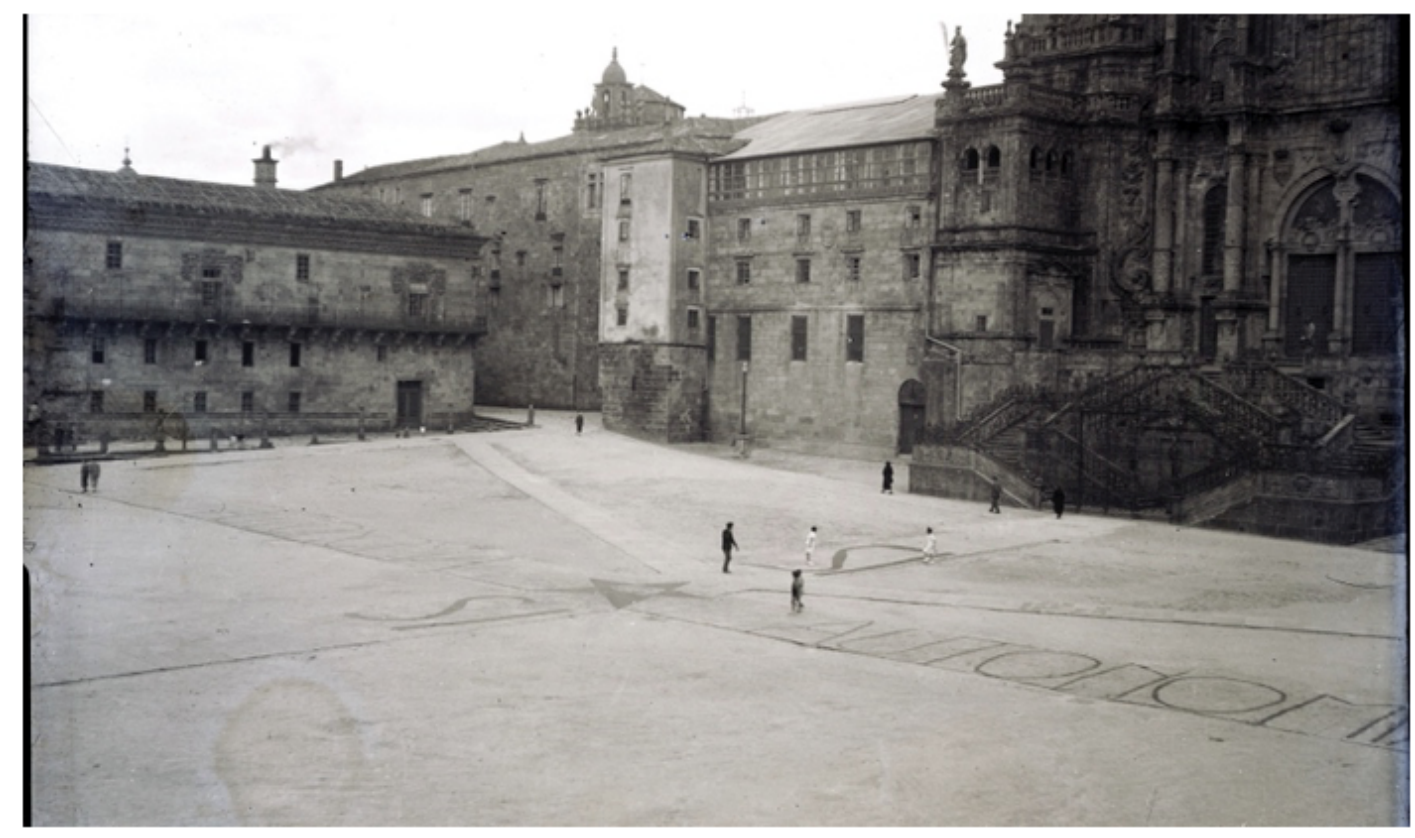


Vista da exposición As miradas de Isaac, Cidade da Cultura de Galicia, 2020. Autor da fotografía: Xosé Díaz.

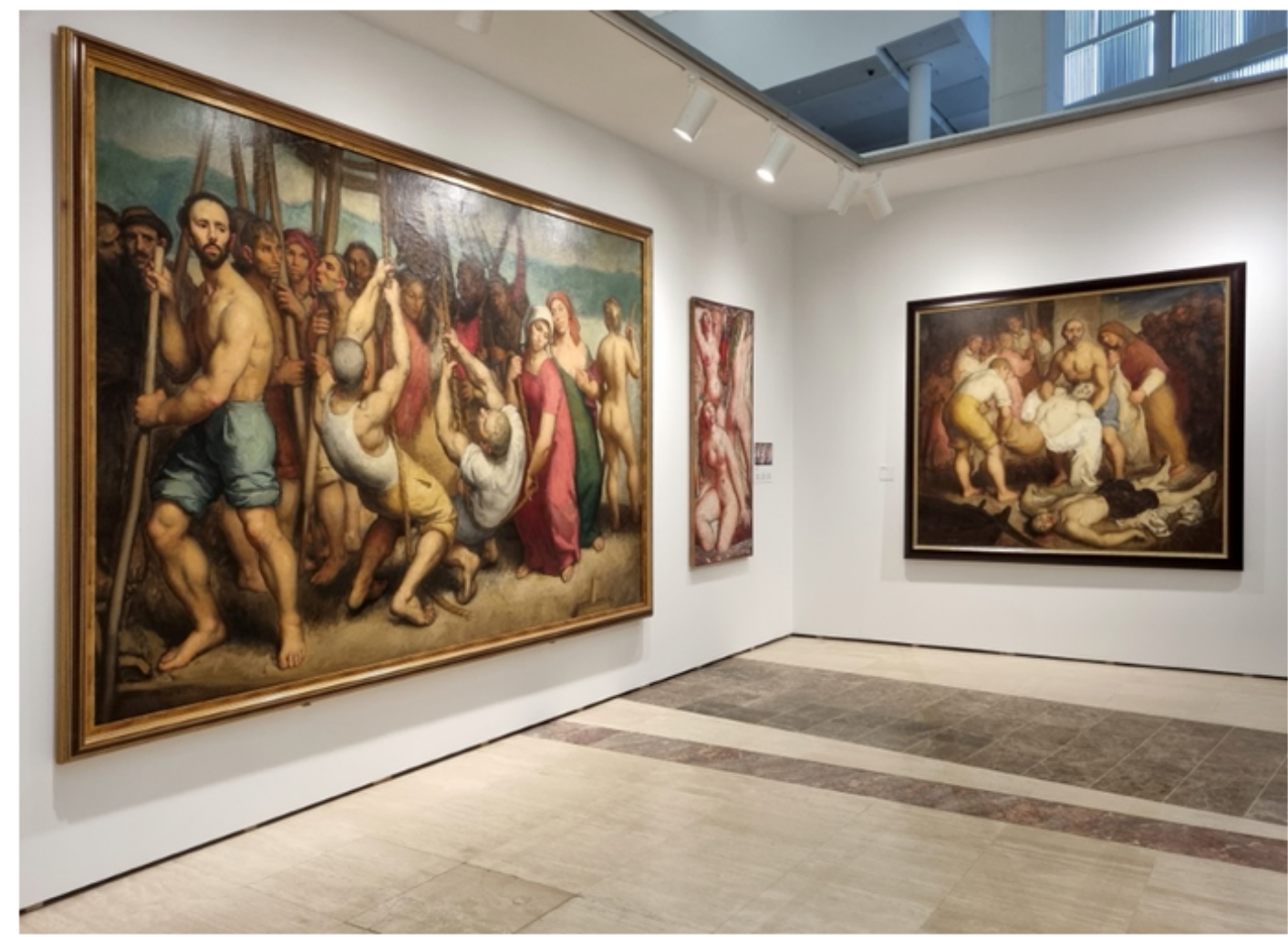

A voz do propio Díaz Pardo funciona como peza vertebradora dos diversos capítulos da mostra, nunha peza audiovisual e sonora que xunta una selección de entrevistas para reconstruír a un Díaz Pardo lúcido e comprometido, condición derivada da honestidade que manifestou en vida e que reflectiría a súa obra. Recuperada por Cecilia Díaz, neta do intelectual, esa narración en primeira persoa acompáñanos dende o arranque da exposición, espazo dedicado a Camilio Díaz Baliño, escenógrafo e deseñador gráfico, pai de Díaz Pardo e figura fundamental na educación artística e no compromiso político do fillo. Precisamente é na adolescencia, e baixo o influxo das ideas que circulaban no círculo familiar, onde a exposición sitúa o espertar público da actitude artística de Díaz Pardo, cunha serie de cartaces para a campaña a favor do Estatuto de autonomía de Galicia e unha pintada no lousado da Praza do Obradoiro, intervención plástica que resume o compromiso político e a visión avanzada e utópica que mantería nas artes o resto da súa traxectoria. Meses despois da intervención no Obradoiro, a vida virou en traxedia cando os falanxistas mataron a Díaz Baliño, quen, na cadea e preocupado polo futuro do fillo, escribiralle: "Prendinlle na cabeza do meu fillo, unha estreliña / forxada na irmandá / e quero ver brillar á lús d'esa estreliña / hasta chegar cegar (...)". Díaz Pardo asumiu a responsabilidade de manter viva a memoria dos vencidos ante o que chamaba o "anxo desmemorizador" ${ }^{1}$, compromiso que nutriu a súa pintura, o deseño, a escrita, as empresas.

Fragmento a fragmento, As miradas de Isaac atende ao inconmensurable legado do autor. É, precisamente, a vontade integral a que singulariza esta exposición respecto de outras achegas que o revisan de xeito máis parcial. Vocación totalizadora pero que asume a imposibilidade de ser definitiva, pois personaxes como Díaz Pardo non se esgotan nunca. Porén, ante a dificultade 
de enfrontarse a todos os ángulos do seu particular microcosmos, a exposición utiliza como fíos condutores a teima da recuperación da memoria e a creación do Laboratorio de Formas, quizais os dous feitos que permiten abordar de xeito condensado a súa traxectoria dende que aos vintesete anos aparcase a profesión de pintor, a que el chamaba "a pintura de cabalete", para saír de Madrid e evitar o encargo que en 1947 lle fixera Fernando Álvarez de Sotomayor, daquela director do Prado, de decorar Cuelgamuros, futuro Valle de los Caídos. Trasládase a Galicia e inicia a traxectoria industrial fundando Cerámicas do Castro, onde se involucra nas investigacións sobre a funcionalidade da arte e a unión entre arte e vida que definirán o seu traballo no futuro. Sería, dende entón, dono de si. Alomenos ata que nunha historia de traizóns e usura, nos primeiros anos dous mil viuse desposeído das empresas que creara.

Vista da exposición As miradas de Isaac, Cidade da Cultura de Galicia, 2020. Autor da fotografía: Xosé Díaz.

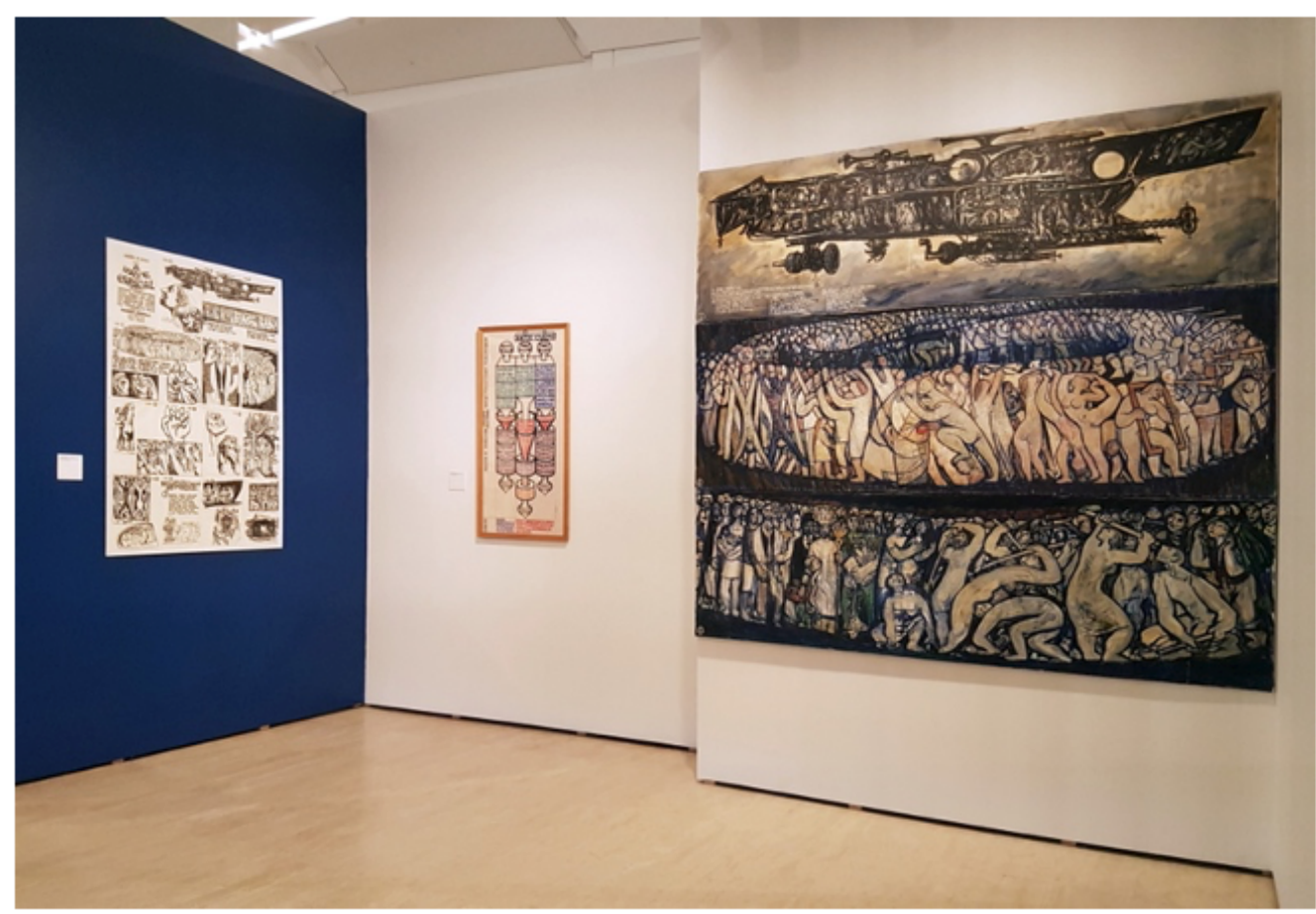


Vista da exposición As miradas de Isaac, Cidade da Cultura de Galicia, 2020. Autor da fotografía: Xosé Díaz.

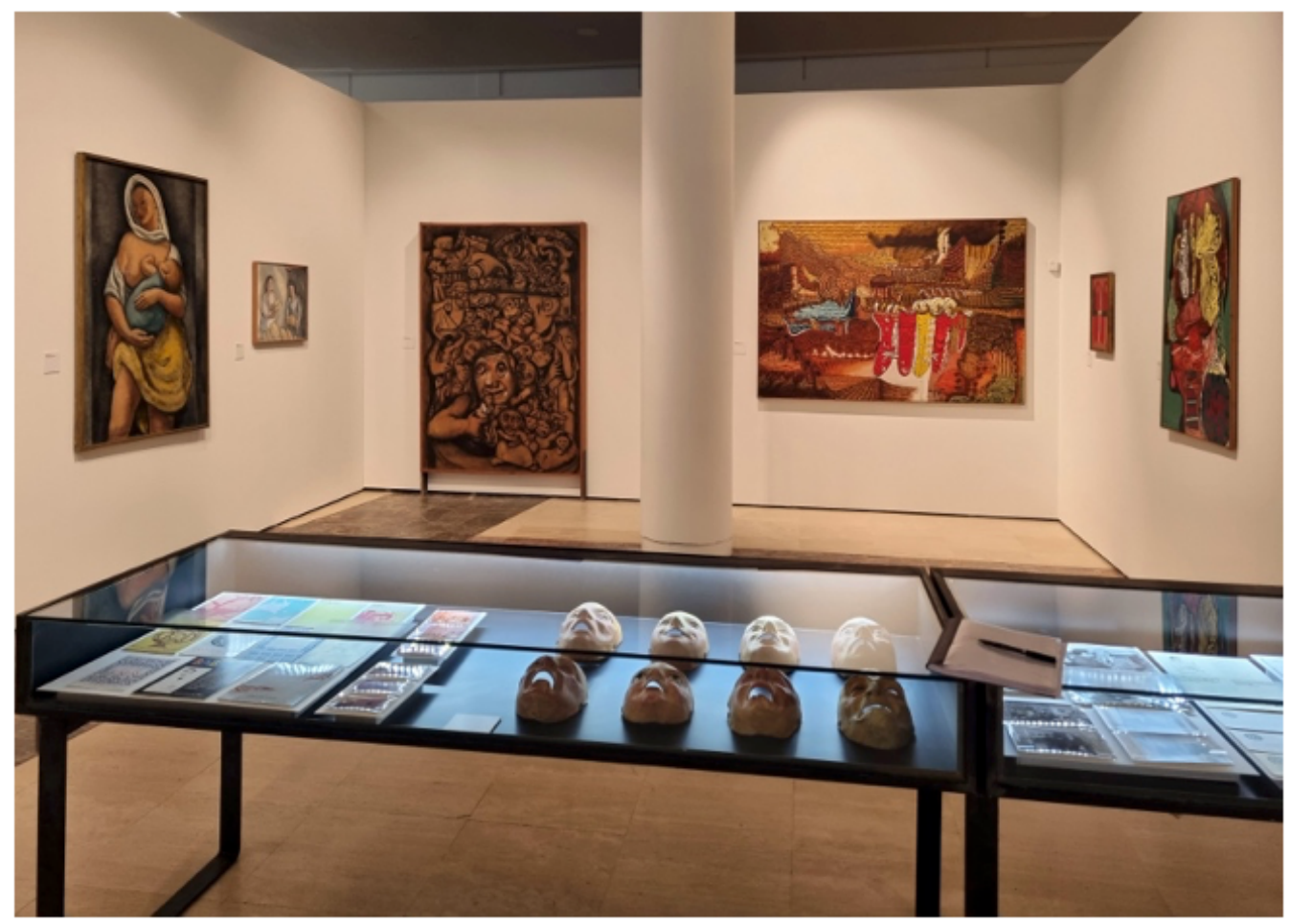

O capítulo da exposición dedicado á pintura, cunha soberbia selección de pezas de grande formato influídas polo clasicismo da posguerra dos anos corenta -O discurso, Os afogados ou $A$ barca de Caronte-, incide nesa denuncia social que reflicte o compromiso ético que guiaría a súa producción plástica e industrial ao abeiro do Laboratorio de Formas (1963). Na exposición dedícanse sendos espazos á reinvención de Sargadelos (1964), á creación de Ediciós do Castro (1963) ou á creación do Museo Carlos Maside (1970), que revisa parte do ideario do museo a través de icónicas pezas como as caretas deseñadas por Castelao para a estrea Os vellos non deben de namorarse (1941) en Buenos Aires. A excepcional colección do museo, cun valor material e inmaterial que lles outorga a condición de exiliados dos autores -ademais de Castelao, a colección inclúe pezas de Maruja Mallo, Arturo Souto, Francisco Vázquez Díaz (Compostela) ou Seoane- foi obxecto, dende o falecemento de Díaz Pardo, dun abandono progresivo que afectou e afecta a súa integridade. A sociedade civil vén reclamando, amparándose na defensa do patrimonio que recolle a Constitución Española e a Ley de Patrimonio Cultural de Galicia (5/2016, de 4 de maio), a incoación do expediente de declaración como Ben de Interese Cultural tanto do edificio do museo como do seu contido, deteriorado e en serio perigo de perda. A estrela que Camilo Díaz Baliño deixou prendida no seu fillo - “(...) xa te deixo prendida no meu fillo / para sempre endexamais"- aloumea agora nas persoas que loitan para que non se perda máis memoria mantendo vivo o seu legado.

\section{REFERENCIAS}

Díaz, M. A.. Luís Seoane. Notas aś súas cartas a Díaz Pardo 1957-1979. Serie Documentos 186. Sada: Edicíos do Castro, 2004.

Fandiño. X. R. Isaac Díaz Pardo. Memoria do compromiso. Santiago de Compostela: Concello de Santiago, 2020. 
Ledo Arias, A. “O Museo Carlos Maside. 0 relato da outra historia.” Grial: revista galega de cultura 209 (2016): 127-137.

Real López, I. El Laboratorio de Formas y las políticas de la memoria. Recuperar las huellas del pasado, Madrid: Editorial Académica Española, 2018.

Rivas, M. “O segredo de Isaac.” El País Galicia, xaneiro 13, 2012. https://elpais.com/diario/2012/01/13/ga licia/1326453502_850215.html [Consultado o 19 de outubro de 2021].

Salgado, D. “Un siglo de Isaac Díaz Pardo, el artista que se negó a pintar Cuelgamuros." eldiario.es, agosto 21, 2020. https://www.eldiario.es/galicia/cultura/siglo-isaac-diaz-pardo-artista-nego-pintar-cuelgamur os_1_6176159.html [Consultado o 19 de outubro de 2021].

VV.AA. As miradas de Isaac: Centenario de Isaac Díaz Pardo (1920-2020). Catálogo de exposición. Santiago de Compostela: Consellería de Cultura, Educación e Universidade, Fundación Cidade da Cultura, 2020.

VV.AA. Sargadelos recuperado: O laboratorio de formas 40 anos despois. Catálogo de exposición. A Coruña: Fundación Luís Seoane, 2008.

Notas

1 Fandiño, Xosé Ramón, “Compostela: infancia e mocidade”, en, VV.AA., As miradas de Isaac: Centenario de Isaac Díaz Pardo (1920-2020), catálogo de exposición, Santiago de Compostela: Consellería de Cultura, Educación e Universidade, Fundación Cidade da Cultura, 2020, p. 52 